\title{
Clinical Spectrum- Cognition, Stages, Functionality among Elderly with Dementia: A Cross-Sectional Study
}

\author{
Niroula N
}

\section{ABSTRACT}

Introduction: Although cognitive and functional impairment are the hallmark features of Dementia but it is often undetected and neglected as a normal part of aging. So we conducted this study on clinical profile of dementia patients. Aim: The aim of this study is to evaluate the Patient's cognitive impairment, functional capacities, and stages of severity of dementia. Methods: A descriptive cross sectional study was conducted among 50 patients aged 60 years and above, of both sexes with the diagnosis of Dementia, admitted in Medicine ward of Nepalgunj Medical College, Nepalgunj, Nepal. The screening of dementia was done using Mini-Mental State Examination tool and the diagnosis of Dementia was confirmed using the International Classification of Disease-10 Diagnostic Criteria for Research. Cognition, functionality and stages of severity of dementia were assessed using Hierarchic Dementia Scale, Functional Autonomy Measurement System, Functional Assessment Staging Test tools respectively. Results: Among a total of 50 dementia patients, the mean and standard deviation of age was $82.4 \pm 6.1$ years, majority of cases $60 \%$ were in the age group $\geq 85$ years and most patients were female $56 \%$. The mean Mini-Mental State Examination score was 9.6 \pm 3.0 , and $50 \%$ had severe impairment of cognition on Hierarchic Dementia Scale. Stage 7 dementia $32 \%$ was most prevalent stage on Functional Assessment Staging and severe deterioration in the functional autonomy was seen in $54 \%$ dementia patients (score $\geq 41$ on Functional Autonomy Measurement System). Conclusion: This study concludes that significant number of elderly patients attending tertiary care hospital suffers from dementia with severe impairment in cognition and functionality in various stages of dementia in the elderly patients.

Keywords: Alzheimer's disease, Cognition, Dementia, Mini Mental State Examination, Neurocognitive disorders

Author:

1. Dr. Niju Niroula

\section{Address for Correspondence:}

\author{
Dr. Niju Niroula \\ Department of Medicine \\ Nepalgunj Medical College and Teaching Hospital \\ Nepalgunj, Banke, Nepal \\ E-mail: dr.nijuniroula@gmail.com
}

\section{INTRODUCTION}

Dementia also referred as Neurocognitivedisorders (NCDs) is adegenerative disease of brain characterizedby progressive impairment of memory, communication skills, planning and personalorganizational ability, and social skills leadingto the progressive decline in the activities ofdaily living and loss of independence. Thecognitive deficits interfere with independencein everyday activities of daily living providinggreat burden for the family members or caretakers. ${ }^{1}$

The most common form of dementia is Alzheimer's disease (AD), accounting for 60 to $80 \%$ of dementia cases. Vascular dementia (VaD), which occurs after a stroke, is the second most common form, accounting for about $10 \%$ of cases. Other types include mixed dementia, dementia with Lewy bodies, and frontotemporal dementia. ${ }^{2}$ Dementia is mostly diagnosed in people over 65 years, but a less prevalent early onset form sometimes develops at earlier age group. ${ }^{3}$ Dementia leads to patient's unusual behaviors, aggression, agitation, forgetting, repetitive questions, culturally inappropriate behaviors, sexual disinhibition, and/or shadowing. ${ }^{4}$ The progressive course of dementia might be classified in three main stages: mild stage- there is still some aptitude for independent life, despite the impact on instrumental activities of daily living; moderate stage- the abilities for independent living are limited and supervision is needed in many activities; severe stagerestricted independence for all activities, including personal hygiene, limited language skills, sometimes with mutism, and often apathy. ${ }^{5}$ Cognitive impairment, even in the mild stages, is a major cause of disability in dementia. ${ }^{6}$

Functional decline, defined as deterioration in self-care skills, is a common and devastating problem for elderly patients with dementia. ${ }^{7,8}$ It is associated with prolonged hospital stay, increased mortality, higher rates of institutionalization, and greater health care expenditure. Recent studies suggested that 34 to $50 \%$ of elderly patients experienced functional decline in dementia..$^{9,10}$ The prevalence of dementia is increasing 
Niroula N : Clinical Spectrum- Cognition, Stages, Functionality among Elderly with Dementia:

A Cross-Sectional Study

globally. ${ }^{11,12}$ It approximately doubles every 5 years in individuals aged 65 to 85 years; from approximately $1 \%$ to $2 \%$ at 65 years, to more than $30 \%$ to $50 \%$ by age 85 years. ${ }^{11}$ About 46.8 million persons suffer from dementia worldwide. ${ }^{13}$ This number is expected to increase to 74.7 million persons by 2030 and to 131.5 million by $2050 .{ }^{14}$ In Nepal except hospital based study we don't have prevalence data butbased on elderly population withat least $5 \%$ prevalence of Dementia among 2.7 million elderly populations in the country as per2011 National census it can be estimated thatthere can be at least 135,000 people suffering fromdementia. ${ }^{15}$ The hospital based study conducted in outpatient departmentin Kathmandu, Nepalhad shown prevalence of dementia as $11 \%$ of which $6 \%$ was vascular dementia and $5 \%$ Alzheimer's dementia. ${ }^{16}$, while another study done in a tertiary-care hospital in eastern Nepal in elderly had reported prevalence of dementia as $6 \% .{ }^{17}$

Most studies employ superficial screening tests and rarely monitor functionality or qualitative aspects in dementia patients. ${ }^{18,19}$ Only a few studies have used a performancebased measure, in which the patient is actually observed and objectively rated on his or her ability to perform various activities of daily living. ${ }^{20}$ In view of the scarcity of studies done in Nepal that precisely evaluate cognitive and (performancebased) functional abilities of dementia patients, we conducted this study on clinical profile of dementia patients with the aim to evaluate their cognitive impairment, functional capacities, and stages of severity of dementia.

\section{METHODS}

This was a descriptive cross-sectional study conducted among 50 patients of aged 60 years and above, of both sexes with the diagnosis of Dementia, admitted in Medicine ward of Nepalgunj Medical College, Nepalgunj, Banke, Nepal, from 25 $5^{\text {th }}$ May 2018 to $25^{\text {th }}$ May 2020 following all appropriate institutional ethics committee clearances. Informed consent was taken from the patients and when they were not able to provide consent because of disease severity, the consent was taken from their relatives. For inclusion, each patient who had scored 24 on the traditional Mini-Mental State Examination-MMSE ${ }^{21}$ and who fulfilled the ICD-10 DCR ${ }^{22}$ criteria for the diagnosis of Dementia, were enrolled into the study. A self-designed semi structured questionnaire was used to obtain the socio-demographic characteristics of the study population.

Each patient after initially scored on MMSE,were then screened for an accurate stratification of cognition using Hierarchic Dementia Scale (HDS). ${ }^{23}$ This instrument consists of 20 subscales assessing a broad spectrum of cognitive abilities. The subscales comprise either five or 10 items in decreasing order of difficulty. On each subscale, the maximum score is 10 , which suggests no impairment. Results between 7 and 9 suggest mild impairment; results between 4 and 6 suggest moderate impairment; finally, results between 0 and 3 suggest severe impairment. The maximum total score on the HDS is 200 points. Older adults who are cognitively intact generally achieve the maximum or close to maximum score. ${ }^{24}$ Even patients with severe dementia are often able to answer correctly the easiest items on the lower end of a subtest. ${ }^{25}$ The validity and reliability of the scale are well established..$^{26}$

Stages of severity of dementia wereassessed by the Functional Assessment Staging Test-FAST, ${ }^{27}$ a hierarchical scale consisting of 16 items. Scores range from normality (FAST stage 1) to severe dementia (FAST stage 7). FAST stages 6 and 7 are subdivided into five and six sub stages, respectively. Reliability andvalidity studies have been performed and showed satisfactory results. ${ }^{28}$

To evaluate the patient's functional capacities, the Functional Autonomy Measurement System (SMAF) was administered. ${ }^{29}$ This 29-item scale measures functional ability in five areas: activities of daily living (ADL: 7 items), mobility ( 6 items), communication (3 items), mental functions (5 items) and instrumental activities of daily living (IADL: 8 items). The disability for each item is scored on a 5-point scale: $0=$ independent, $0.5=$ with difficulty, 1 = with supervision, 2 = with help and 3 = dependent. Higher score is indicative of severe autonomy impairment.This version of the scale has shown good test-retest and inter-rater reliability. ${ }^{30}$ Data were analyzed using SPSS version16 (Chicago, Illinois, USA). Descriptive analysis was performed.

\section{RESULTS}

Among a total of 50 dementia patients (Alzheimer's dementia $44(88 \%)$ and Vascular dementia $6(12 \%)$ included in this study, females 28 (56\%) outnumbered males 22 (44\%). The mean and SD of age of patients was $82.4 \pm 6.1$ years, majority of cases $60 \%$ were in the age group 85 years and above.Dementia was found more than 3 times higher in rural populations $(78 \%)$ than in urban populations (22\%).The risk of dementia was considerably higher among those with no formal education $(62 \%)$, compared to those with primary $(18 \%)$ or secondary (12\%) or Higher secondary/above (8\%). There was a considerably higher prevalence of dementia among respondents who were unemployed (60\%) compared to those who were employed/retired (40\%). (Table-I) 
Niroula N : Clinical Spectrum- Cognition, Stages, Functionality among Elderly with Dementia:

A Cross-Sectional Study

\begin{tabular}{|c|c|c|}
\hline & Variables & $\begin{array}{l}\text { Frequency \% } \\
\qquad n=50\end{array}$ \\
\hline \multirow{3}{*}{ Age in years } & $65-74$ & $\begin{array}{c}8 \\
(16 \%)\end{array}$ \\
\hline & $75-84$ & $\begin{array}{c}12 \\
(24 \%)\end{array}$ \\
\hline & $\geq 85$ & $\begin{array}{c}30 \\
(60 \%)\end{array}$ \\
\hline \multirow{2}{*}{ Gender } & Male & $\begin{array}{c}22 \\
(44 \%)\end{array}$ \\
\hline & Female & $\begin{array}{c}28 \\
(56 \%)\end{array}$ \\
\hline \multirow{2}{*}{ Residence } & Urban & $\begin{array}{c}11 \\
(22 \%)\end{array}$ \\
\hline & Rural & $\begin{array}{c}39 \\
(78 \%)\end{array}$ \\
\hline \multirow{4}{*}{ Education } & Illiterate & $\begin{array}{c}31 \\
(62 \%)\end{array}$ \\
\hline & Primary & $\begin{array}{c}9 \\
(18 \%)\end{array}$ \\
\hline & Secondary & $\begin{array}{c}6 \\
(12 \%)\end{array}$ \\
\hline & Higher Secondary and above & $\begin{array}{c}4 \\
(8 \%)\end{array}$ \\
\hline \multirow{2}{*}{ Occupation } & Employed or retired & $\begin{array}{c}20 \\
(40 \%)\end{array}$ \\
\hline & Unemployed & $\begin{array}{c}30 \\
(60 \%)\end{array}$ \\
\hline
\end{tabular}

Table I : Distribution on the basis of socio demographic variables

Regarding screening for cognition, initial traditionalMMSE mean result was 9.6 \pm 3.0 . Then the further stratification of cognition using Hierarchic Dementia Scale-HDS showed 25 (50\%) patients had severe impairment of cognition.More than two third of the dementia patients 27 (54\%) showed severe deterioration in their functional autonomy (score $\geq 41$ on the Functional Autonomy Measurement System-SMAF). (Table-II)

\begin{tabular}{ccc|} 
& Variables & $\begin{array}{c}\text { Frequency } \% \\
\mathbf{n}=50\end{array}$ \\
& 0-3 (Severe impairment) & 25 \\
& & $(50 \%)$ \\
$\begin{array}{c}\text { Cognition } \\
\text { (HDS) }\end{array}$ & $4-6$ (Moderate impairment) & 16 \\
& 7-9 (Mild impairment) & $(32 \%)$ \\
& & 9 \\
& $0-29$ (No to mild dependency) & $(18 \%)$ \\
Functionality & & $(16 \%)$ \\
(SMAF) & $29.1-40$ (Moderate dependency) & 15 \\
& & $(30 \%)$ \\
& $\geq 41$ (Severe dependency) & 27 \\
& & $(54 \%)$
\end{tabular}

Table II : Distribution on the basis of Cognition and Functionality

The different categories of stages of dementia in Functional Assessment Staging Test-FAST showed that the stage 7 dementia $32 \%$ was the most prevalent stage of dementia. Results can be seen in Table-III.

\begin{tabular}{|c|c|c|}
\hline \multicolumn{2}{|c|}{ Stages of dementia (FAST) } & $\begin{array}{l}\text { Frequency \% } \\
\quad n=50\end{array}$ \\
\hline Mild dementia & $\begin{array}{l}\text { Stage } 4 \\
\text { (IADLs becomes affected) }\end{array}$ & $\begin{array}{c}9 \\
(18 \%)\end{array}$ \\
\hline $\begin{array}{l}\text { Moderate } \\
\text { dementia }\end{array}$ & $\begin{array}{l}\text { Stage } 5 \\
\text { (Needs help selecting proper attire) }\end{array}$ & $\begin{array}{c}15 \\
(30 \%)\end{array}$ \\
\hline \multirow{4}{*}{$\begin{array}{l}\text { Moderately } \\
\text { Severe } \\
\text { dementia }\end{array}$} & Stage 6 & $\begin{array}{c}10 \\
(20 \%)\end{array}$ \\
\hline & 6a (Needs help putting on clothes) & $\begin{array}{c}5 \\
(10 \%)\end{array}$ \\
\hline & 6b (Needs help bathing) & $\begin{array}{c}3 \\
(6 \%)\end{array}$ \\
\hline & $6 c$ (Needs help toileting) & $\begin{array}{c}2 \\
(4 \%)\end{array}$ \\
\hline \multirow{3}{*}{$\begin{array}{l}\text { Severe } \\
\text { dementia }\end{array}$} & Stage 7 & $\begin{array}{c}16 \\
(32 \%)\end{array}$ \\
\hline & 7a (Speaks 5-6 words during day) & $\begin{array}{c}12 \\
(24 \%)\end{array}$ \\
\hline & 7b (Speaks only 1 word clearly) & $\begin{array}{c}4 \\
(8 \%)\end{array}$ \\
\hline
\end{tabular}

Table III : Distribution on the basis of Stages of dementia

\section{DISCUSSION}

In our research among a total of 50 patients, dementia prevalence increased with age, mean age of presentation was $82.4 \pm 6.1$ years. The figure rose from $16 \%$ for patients younger than 74 years, $24 \%$ for younger than 84 years to $60 \%$ for 85 years and beyond of age. This was consistent with the results of previous studies pointing out the association between age and prevalence of dementia. ${ }^{31,32}$

The most common form of dementia in our study was Alzheimer's dementia (88\%) followed by Vascular dementia (12\%). Various epidemiological and clinical studies have reported $A D$ as the most common cause of dementia followed by $\mathrm{VaD} .{ }^{33}$

In the present study, $56 \%$ of patients with dementia were females while $44 \%$ were males. This result is in line with the findings of the majority of the previous research, which have reported higher rates of dementia in women. Similar gender differences were also reported in many studies. ${ }^{34,35}$ The interaction between genes, hormones, and the social environment may be the main reasons for this difference between genders. ${ }^{33} \mathrm{As}$ life expectancy for women is higher than men and age is major risk factor for dementia, soincidence of dementia is higher in women ${ }^{36}$

Dementia was found more than 3 times higher in rural populations $(78 \%)$ than in urban populations $(22 \%)$ in our study. Many studies reported the association between living in rural place and risk of dementia. This may be due to the fact that patients from rural background were less educated as compared to urban and low level education has a higher risk of cognitive decline and dementia in people living in rural areas. ${ }^{37,38}$ 
Niroula N : Clinical Spectrum- Cognition, Stages, Functionality among Elderly with Dementia:

A Cross-Sectional Study

The risk of dementia in our study was seen considerably higher among those with no formal education (62\%), compared to those with primary $(18 \%)$ or secondary $(12 \%)$ or Higher secondary/above (8\%). This is comparable to other studies which also suggest that higher education levels are associated with a reduced risk of cognitive decline and dementia. ${ }^{39}$ The effect of education on the cognitive decline can be explained using the 'cognitive reserve hypothesis' with a positive correlation that a low level of education is related to an increased incidence of dementia.Mental and intellectually challenging activities involved in educational and complex mental activities is recognized as having a powerful role in maintaining or enhancing brain reserve and is thus protective against the risk of dementia in old age. ${ }^{40}$

Another point we would like to highlight about this study is that the rate of dementia prevalence was significantly lower among employed or retired individuals (40\%) than unemployed patients (60\%). Several studies have shown that not having an active job throughout one's life increases the risk of dementia due to a reduction in cognitive reserves. ${ }^{41}$

In our study the cognitive abilities assessedusing Hierarchic Dementia Scale showed $50 \%$ patients had severe impairment of cognition which is in line with the previous research where severe deficits in cognitive function was reported in dementia patients as assessed by HDS tool. ${ }^{42}$

The functional capacities of patients in our study wasseverely impaired, more than two third of the dementia patients 27 (54 $\%)$ showed severe deterioration in their functional autonomy (score $\geq 41$ on the Functional Autonomy Measurement SystemSMAF).Some cross-sectional studies have noted greater prevalence rates offunctional declineassociated with increasing age among older persons with dementia. ${ }^{43,44,45}$

The different categories of stages of dementia in Functional Assessment Staging Test-FAST in our study showed that the stage 7 dementia $32 \%$ was the most prevalent stage. These findings have been consistent with a study done in Korean patients, which elucidated $46 \%$ patients at Functional Assessment Staging Scale (FAST) stage $6 \mathrm{~d}$ or above. ${ }^{46}$ Similar results noted in other studies. ${ }^{47,48}$

\section{LIMITATIONS}

The findings in this study are based on a single center outpatient based samples, so generalization to other settings might not be appropriate. A larger sample size may be helpful to confirm the contributing factors. So, if we want to produce more accurate conclusion for our present study, we need to carry out this study over large number of samples from different regional part of Nepal. Further studies should be conducted with different samples using alternative measures, with the aim to find the same correlations or new results through the application of different statistical techniques.

\section{CONCLUSION}

This study concludes that significant number of elderly patients attending tertiary care hospital suffers from dementia with severe impairment in cognition and functionality. It shows the importance for clinical, multidisciplinary teams along with adequate diagnostic modalities to understand the stages of the dementia with progressive decline in cognitive and functional capacities which may help in a timely diagnosis and may direct future developments with regard to specific techniques to deal with dementia patients.

\section{REFERENCES}

1. Jeste D. Neurocognitive Disorders. American Psychiatric Association.Diagnostic and Statistical Manual ofMental Disorders: DSM-5. 5th ed. 2013.p 602-14.

2. Alzheimer's Association. 2016 Alzheimer's disease facts and figures. Alzheimers Dement. 2016;12(4):459-509.

3. Povova, Ambroz P, Bar M, Pavukova V, Sery O, Tomaskova H, Janout V. Epidemiological of and risk factors for Alzheimer's disease: a review. Biomed Pap Med FacPalackyUniv Olomouc. 2012;156(2):108-14.

4. Korczyn AD. Mixed dementia-the most common cause of dementia. Ann N Y AcadSci 977: 2002;129-34.

5. American Psychiatric Association. Diagnostic and statistical manual of mental disorders. 4th ed. Washington: American Psychological Association; 1994.

6. FinkeI SI, Silva JC, Cohen G, Miller S, Sartorius N, et al. Behavioral and psychological signs and symptoms of dementia: a consensus statement on current knowledge and implications for research and treatment. IntPsychogeriatr 1997;8:497-500.

7. Gill TM, Allore HG, Holford TR, Guo Z. Hospitalization, restricted activity, and the development of disability among older persons. JAMA.American Medical Association (AMA); 2004 Nov 3;292(17):2115.

8. Chang HH, Tsai SL, Chen CY, Liu WJ. Outcomes of hospitalized elderly patients with geriatric syndrome: report of a community hospital reform plan in Taiwan. Arch GerontolGeriatr. 2010;50(Suppl 1):S30-3.

9. Mehta KM, Pierluissi E, Boscardin WJ, Kirby KA, Walter LC, Chren MM, Palmer RM, Counsell SR, Landefeld CS. A clinical index to stratify hospitalized older adults according to risk for new-onset disability. J Am Geriatr Soc. 2011;59:1206-16.

10. McCusker J, Kakuma R, Abrahamowicz M. Predictors of functional decline in hospitalized elderly patients: a systematic review. J Gerontol A BiolSci Med Sci. 2002;57:M569-77.

11. Alzheimer's Association. 2018 Alzheimer's disease facts and figures. Alzheimers Dement 2018;14(3):367-429.

12. Prince MJ, Wimo A, Guerchet MM, et al. World alzheimer report 2015 - the global impact of dementia: an analysis of prevalence, incidence, cost and trends. London: Alzheimer's Disease International (ADI); 2015.

13. Alzheimer's Disease International, editor. World Alzheimer Report. 2016. Available from: https://www.alz.co.uk/research/ world-report-2016[cited 2018 Jan 22] 
Niroula N : Clinical Spectrum- Cognition, Stages, Functionality among Elderly with Dementia:

A Cross-Sectional Study

14. Van Rensbergen G, Nawrot T. Medical Conditions of Nursing HomeAdmissions. BMC Geriatr.2010;10:46.

15. National Population and Housing census 2011 (National report). Government of Nepal, National Planning Commission Secretariat, Central Bureau of Statistics, Kathmandu, Nepal, 2012

16. Khattri JB, Nepal MK et al. Study of depression among geriatric population in Nepal. Nepal Med Coll J. 2006; 8(4):220-3.

17. Shakya DR. Psychiatric morbidities of elderly psychiatry outpatients in a tertiary-care hospital. Journal of College of Medical Sciences Nepal 2011;7(4):1-8

18. Doraiswamy PW, Bieber F, Kaiser L, Krishnan KR, Reuning-Scherer J, Gulanski B. The Alzheimer's disease assessment scale: patterns and predictors of baseline cognitive performance in multicenter Alzheimer's disease trials. Neurology.1997;48(6):1511-7.

19. Franssen $\mathrm{EH}$, Kluger $\mathrm{A}$, Torassian $\mathrm{CL}$. The neurologic syndrome of severe Alzheimer's disease. Arch Neurol. 1993;50(10):1029-39.

20. Nussbaum PD, Goreczny A, Haddad L. Cognitive correlates of functional capacity in elderly depressed versus patients with probable Alzheimer's disease. NeuropsycholRehabil. 1995;5(4):333-40.

21. Folstein MF, Folstein SE, McHugh PR. "Mini-mental state": a practical method for grading the cognitive state of patients for the clinician. J Psychiatr Res. 1975;12(3):189-98.

22. World Health Organization. The ICD-10 Classification of Mental and Behavioural Disorders: Diagnostic Criteria for Research. Geneva: World Health Organization; 1993.

23. Cole MG, Dastoor DP: A new hierarchic approach to the measurement of dementia. Accurate results within 15 to 30 minutes. Psychosomatics 1987, 28(6):298-301.

24. Demonet JF, Doyon B, Ousset PJ, PuelM,Mahagne $\mathrm{MH}$, Cardebat D, Duchein C, VialaMF, Agniel A, Vellas B, et al. Revue neurologique 1990, 146(8-9):490-501.

25. Ronnberg L, Ericsson K: Reliability and validity of the Hierarchic Dementia Scale. International Psychogeriatrics 1994, 6(1):87-94.

26. Bickel H: The Hierarchic Dementia Scale: usage. International psychogeriatrics/IPA 1996, 8(2):213-24.

27. Reisberg B. Functional assessment staging (FAST). Psychopharmacol Bull 1988;24(4):653-9.

28. Sclan SG, Reisberg B. Functional assessment staging (FAST) in Alzheimer's disease: Reliability, validity and ordinaliry, IntPsychogeriatr 1992;4(Suppl1):55-69.

29. Hebert R, Carrier R, Bilodeau A: The Functional Autonomy Measurement System (SMAF): description and validation of an instrument for the measurement of handicaps. Age and ageing 1988, 17(5):293-302.

30. Desrosiers J, Bravo G, Hebert R, Dubuc N: Reliability of the revised functional autonomy measurement system (SMAF) for epidemiological research. Age and ageing 1995, 24(5):402-06.

31. Prince M, Knapp M, Guerchet M, et al. Dementia UK: Overview. 2014.https://www.alzheimers.org.uk/about-us/policy-andinfluencing/dementia-uk report.Accessed January 1, 2019.

32. Fishman E. Risk of developing dementia at older ages in the United States. Demography. 2017;54(5):1897-1919.

33. Kalaria RN, Maestre GE, Arizaga R, Friedland RP, Galasko D et al. Alzheimer's disease and vascular dementia in developing countries: prevalence, management, and risk factors. Lancet Neurol 2008; 7:812-26.

34. Krishnaswamy S, Kadir K, Ali RA, SidiH,Mathews S: Prevalence of dementia among Malaysia in an urban settlement in Malaysia. Neurol J Southeast Asia 1997; 2: 159-62.

35. Kim JM, Stewart R, Prince $M$, Shin IS, YoonJS: Diagnosing dementia in a developing nation: an evaluation of the GMSAGECAT algorithm in an older Korean population. Int J Geriatr Psychiatry 2003; 18: 331-36.

36. Letenneur L, Gilleron V, Commenges. Are sex and educational level independent predictors of dementia and Alzheimer's disease? Incidence data from the PAQUID project. JNeurolNeurosurg Psychiatry 1999; 66:177-183.

37. Llibre Rodríguez JJ, Ferri CP, Acosta D, et al. Prevalence of dementia in Latin America, India, and China: a population-based cross-sectional survey. Lancet.;2008;372:464-74.

38. Russ, T. C., Batty, G. D., Hearnshaw, G. F., Fenton, C., \& Starr, J. M. Geographical variation in dementia: systematic review with meta-analysis. International journal of epidemiology 2012; 41(4), 1012-32.

39. Qiu C, Bäckman L, Winblad B, Agüero-Torres H, Fratiglioni L. The influence of education on clinically diagnosed dementia incidence and mortality data from the Kungsholmen Project. Arch Neurol 2001;58:2034-9.

40. Valenzuela MJ, Sachdev P: Brain reserve anddementia: a systematic review. Psychol Med 2006; 36: 441-54.

41. Jorm AF, Rodgers $B$, Henderson AS, Korten $A E$, Jacomb $\mathrm{PA}$, Christensen $\mathrm{H}$, et al. Occupation type as a predictor of cognitive decline and dementia in old age: Age and Ageing 1998;27(4):477-83.

42. Cooper B, Bickel H, Schaufele M. Early development and progression of dementing illness in the elderly: a generalpractice based study. Psychological Medicine. Cambridge University Press; 1996;26(2):411-9.

43. Branch LG, Kak S, Kniepmann K, et al. A prospective study of functional status among community elders. Am J PublicHealth 1984;74:266-8.

44. Beckett LA, Brock DB, Lemke JH, et al. Analysis of changein self-reported physical function among older persons in fourpopulation studies. Am J Epidemiol 1996;143:766-78.

45. Hebert R, Brayne C, Spiegelhalter D. Incidence of functional decline and improvementin a community-dwelling very elderly population. Am J Epidemiol 1997;145:935-44.

46. Sampson EL, White N, Leurent B, et al. Behavioural and psychiatric symptoms in people with dementia admitted to the acute hospital: prospective cohort study. $\mathrm{Br} J$ Psychiatry. 2014;205(3):189-96.

47. Na HR, Kim SY, Chang YH, et al. Functional assessment staging (FAST) in Korean patients with Alzheimer's disease. J Alzheimers Dis. 2010;22(1):151-58. doi:10.3233/JAD-2010-100072.

48. Bae NL, Lee KH, Lee K, Kwak KP. Efficacy of cognitive training in community dwelling elderly. J Korean Geriatr Psychiatry 2015;19:91-96. 